06

\title{
Влияние содержания технического углерода на температурные зависимости электропроводности полимерного композита
}

\author{
() А.М. Зюзин, А.А. Карпеев, Н.В. Янцен \\ Национальный исследовательский Мордовский государственный университет \\ им. Н.П. Огарева, Саранск, Россия \\ E-mail: zyuzin.am@rambler.ru
}

Поступило в Редакцию 20 июля 2021 г.

В окончательной редакции 23 сентября 2021 r.

Принято к публикации 24 сентября 2021 г.

Установлено, что в области порога перколяции в зависимости от доминирования того или иного механизма проводимости температурная зависимость удельного объемного сопротивления $\rho(T)$ полимерного композита на основе матрицы из этиленвинилацетата существенным образом трансформируется. С возрастанием содержания технического углерода происходит уменьшение на несколько порядков максимальной величины относительного удельного сопротивления $\rho(T)_{\max } / \rho_{20}$ на его температурной зависимости. Пероксидная сшивка макромолекул матрицы приводит к изменению характера температурной зависимости удельного сопротивления.

Ключевые слова: полимерные композиты, технический углерод, электропроводность, температурная зависимость.

DOI: 10.21883/PJTF.2022.01.51876.18965

Электропроводящие полимерные композиционные материалы вызывают повышенный интерес исследователей и разработчиков новых материалов из-за их широкого практического применения [1-3]. Применение технического углерода (ТУ) в качестве наполнителя, обеспечивающего электропроводность, несмотря на сравнительно высокий порог перколяции $(C \approx 15 \%)$, не усложняет процедуру смешивания для достижения необходимой гомогенности композитов и обеспечивает требуемые физико-механические и технологические характеристики при производстве, например, экранных оболочек силовых кабелей высокого напряжения. Использование углеродных нанотрубок из-за специфики их геометрии и пониженного содержания $(\sim 1.5-2 \%)$ не исключает вероятность возникновения локальных центров разряда и пробоя в местах выхода нанотрубок за поверхность проводящего слоя композита. Исследованиям физических свойств композиционных материалов, наполненных ТУ, посвящено большое число работ как у нас в стране, так и за рубежом [2-8].

Целью настоящей работы является исследование влияния содержания ТУ на температурные зависимости электропроводности полимерного композита на основе матрицы из этиленвинилацетата. В качестве наполнителя, обеспечивающего электропроводность, использовался ТУ C40 серии „ОМСАRB“, содержание $(C)$ которого в полимерной матрице изменялось от 15 до 35 массовых долей. Изготовление композитов проводилось путем смешивания на лабораторном экструдере EX30. Затем часть материалов выдерживалась в расплаве дикумилпероксида при температуре $55^{\circ} \mathrm{C}$ в течение $30 \mathrm{~min}$. Образцы в виде пластин толщиной $2 \mathrm{~mm}$ были получены прессованием. Для регистрации температурных зависимостей удельного сопротивления $\rho(T)$ образцы прямоугольной формы размером $10 \times 100 \mathrm{~mm}$ помещались в печь SNOL 58/350, температура изменялась с шагом $3-5^{\circ} \mathrm{C}$ и поддерживалась с точностью $\pm 1^{\circ} \mathrm{C}$. При каждой температуре измерений образец выдерживался в течение $5 \mathrm{~min}$. Сопротивление образцов со значением удельного сопротивления $\rho \geqslant 10^{6} \Omega \cdot \mathrm{cm}$ измерялось с помощью прибора Megger MIT1025 по двухзондовой схеме, с меньшим значением $\rho-$ по четырехзондовой. Композиты с разным содержанием ТУ были также исследованы методом дифференциальной сканирующей калориметрии (ДСК) с помощью прибора METTLER TOLEDO DSC 823e.

На рис. 1 представлены зависимости удельного сопротивления при температуре $20^{\circ} \mathrm{C}\left(\rho_{20}\right)$ от содержания ТУ

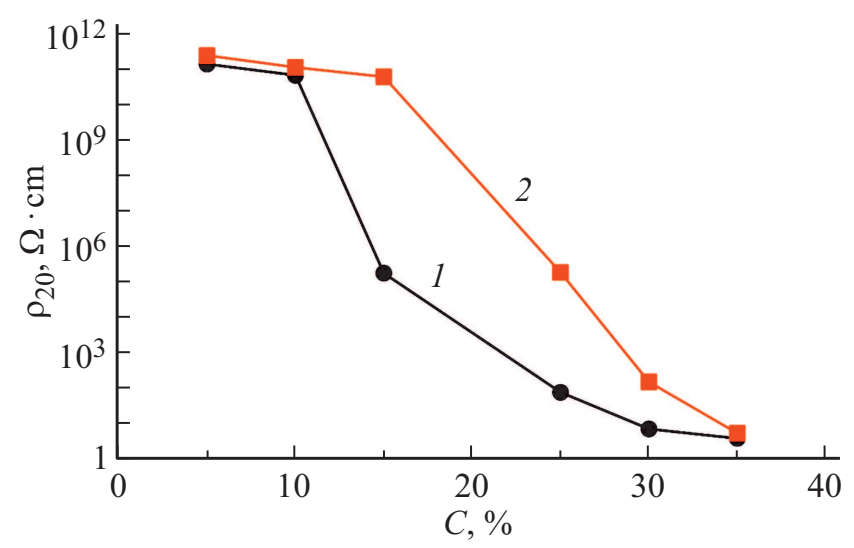

Рис. 1. Зависимости удельного сопротивления композита от содержания ТУ при температуре $20^{\circ}$ C. 1 - исходные образцы, 2 - образцы, насыщенные пероксидом. 
для насыщенных и не насыщенных пероксидом образцов. Из представленных на этом рисунке результатов следует, что области перколяции соответствует диапазон концентраций ТУ в составе композита $C \approx 10-25 \%$ для ненасыщенных и $C \approx 15-30 \%$ для образцов, насыщенных пероксидом. Механизм, обусловливающий резкое (особенно в области перколяции) возрастание $\rho$ в результате насыщения пероксидом, описан в работе [9]. Прямые и обратные (при понижении температуры) температурные зависимости относительных значений $\rho(T) / \rho_{20}$ для исходных образцов с различным содержанием ТУ приведены на рис. $2, a-c$. Там же представлены прямые и обратные кривые ДСК, которые построены с учетом коэффициента, учитывающего значение $C$. Для этого они скорректированы (умножены) по ординате на коэффициент $k=1 /(1-C)$. Из приведенных кривых ДСК видно, что положения основного (доминирующего) и высокотемпературного пика с меньшей интенсивностью, обусловленного наличием дополнительной полимерной кристаллической фазы [10], практически не изменяются. В то же время температурные зависимости $\rho(T)$ претерпевают существенную трансформацию с увеличением содержания ТУ. Как видно из рис. 2, $a$, для образца с концентрацией $C=15 \%$, примерно соответствующей порогу перколяции, на прямой зависимости $\rho(T) / \rho_{20}$ максимум $\rho(T)_{\max }$ наблюдается при температуре, существенно менышей точки плавления основной полимерной кристаллической фазы (температуры $T \approx 91^{\circ} \mathrm{C}$, соответствующей пику на кривой ДСК). Положение $\rho(T)_{\max }\left(T \approx 86^{\circ} \mathrm{C}\right)$ примерно соответствует началу процесса плавления этой фазы. В точке плавления наблюдается резкий спад $\rho(T) / \rho_{20}$. На обратной зависимости $\rho(T)$ максимум $\rho(T)_{\max }$ наблюдается при температуре, соответствующей завершению процесса кристаллизации, в точке кристаллизации происходит наиболее резкое возрастание $\rho(T)$.

При такой $(C=15 \%)$ концентрации ТУ проводящая сетка, образуемая частицами ТУ, еще не сформирована и основными механизмами проводимости являются прыжковый механизм, обусловленный перескоками электронов, обладающих энергиями около уровня Ферми, но превышающими величину потенциального барьера, и механизм, связанный с туннелированием электронов через потенциальные барьеры между близко (менее $5 \mathrm{~nm}$ ) расположенными проводящими частицами ТУ [11]. Наличие в образцах с $C=15 \%$ ТУ именно такого механизма проводимости подтверждается тем, что зависимость плотности тока $j$ от напряженности поля $E$ (вольт-амперная характеристика) с хорошей точностью описывается соотношением Фаулера-Нордгейма [12]:

$$
j=A E^{2} e^{-\frac{B}{E}},
$$

где $A$ и $B-$ постоянные. В образцах с $C=25,30$ и $35 \%$ зависимость $j(E)$ была линейной.

Данное обстоятельство и обусловливает особенности, присущие температурной зависимости $\rho(T)$, т.е. на прыжковый механизм проводимости и вероятность туннелирования носителей тока доминирующее влияние оказывают термостимулированные процессы, происходящие в области температур, предшествующих точке плавления полимерной кристаллической фазы композита.

С увеличением $C$ до $25 \%$ (рис. $2, b$ ) максимум на зависимости $\rho(T)$ смещается в область более высоких температур. При такой концентрации уменьшается расстояние между частицами ТУ, и наряду с возрастанием вклада, связанного с туннелированием носителей тока, заметный вклад в электропроводность начинает вносить механизм, обусловленный сеткой непосредственно контактирующих между собой проводящих частиц ТУ и их агломератов, т.е. так называемой омической проводимостью.

При увеличении содержания ТУ до 35\%, когда, как следует из значений $\rho_{20}$ для этого образца, формируется уже более плотная проводящая сетка частиц ТУ, которая и определяет доминирующий механизм проводимости, температурная зависимость $\rho(T)$ становится иной (рис. 2,c). Видно, что для такой концентрации при температуре, соответствующей точке плавления полимерной кристаллической фазы, происходит максимально быстрое возрастание $\rho(T)$, обусловленное разрушением мостиков проводимости, образованных частицами ТУ. Максимум $\rho(T)$ наблюдается уже при температуре $T \approx 98^{\circ} \mathrm{C}$, т. е. при температуре не начала, как в случае образца с $C=15 \%$, а окончания процесса плавления полимерной кристаллической фазы. Уменьшение $\rho(T)$ при дальнейшем увеличении $T$ связано с восстановлением мостиков проводимости в результате агломерации частиц ТУ из-за возрастания их подвижности. На обратных зависимостях максимум $\rho(T)$ примерно соответствует температуре начала кристаллизации этой фазы. Из рис. 2, с также видно, что при концентрации $C=35 \%$ доля второй (более высокотемпературной) полимерной кристаллической фазы, инициируемой частицами ТУ, возрастает и становится более заметным ее влияние на температурную зависимость $\rho(T)$ [10]. Из рис. 2 и таблицы видно, что с ростом $C$ происходит резкое уменьшение относительных изменений $\rho_{\max } / \rho_{20}$. Также резко уменьшается величина температурного коэффициента сопротивления (ТКС)

$$
\beta=\frac{1}{\rho_{20}} \frac{\partial \rho}{\partial T},
$$

причем как его положительных (ПТКС), так и отрицательных (ОТКС) значений, определенных в точках перегиба на соответствующих участках зависимости $\rho(T) / \rho_{20}$. Данное уменьшение можно объяснить тем, что, как отмечено выше, с ростом $C$ формируется более плотная проводящая сетка, образуемая частицами ТУ и их агломератами, а также тем, что с уменьшением доли полимерной матрицы уменьшается степень ее влияния на изменение состояния этой сетки. Из таблицы также следует, что для образца с $C=15 \%$ ОТКС примерно 


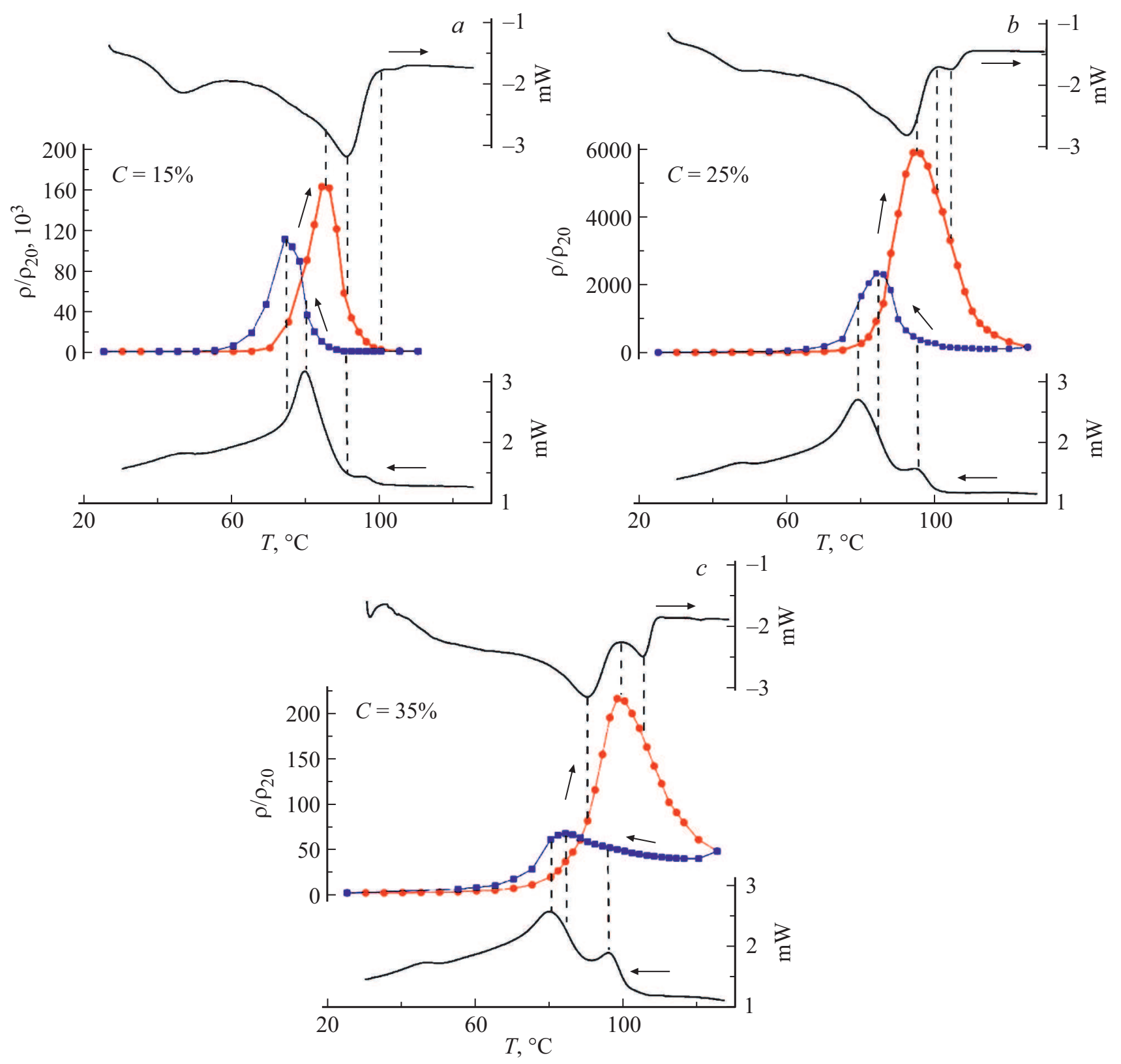

Рис. 2. Прямые и обратные температурные зависимости удельного сопротивления $\rho(T) / \rho_{20}$ исходного композита с различным содержанием ТУ. Сверху и снизу приведены соответствующие кривые ДСК.

Параметры образцов композитов

\begin{tabular}{|c|c|c|c|c|c|c|c|}
\hline \multirow{2}{*}{$C, \%$} & \multicolumn{4}{|c|}{ Исходные образцы } & \multicolumn{3}{|c|}{$\begin{array}{c}\text { Образцы, насыщенные } \\
\text { пероксидом }\end{array}$} \\
\hline & $\begin{array}{c}\rho_{20} \\
\Omega \cdot \mathrm{cm}\end{array}$ & $\rho_{\max } / \rho_{20}$ & ПТКС & ОТКС & $\rho_{20}, \Omega \cdot \mathrm{cm}$ & $\rho_{\max } / \rho_{20}$ & ПТКС \\
\hline $\begin{array}{l}15 \\
25 \\
30 \\
35\end{array}$ & $\begin{array}{c}159000 \\
68.5 \\
6.3 \\
3.4\end{array}$ & $\begin{array}{c}161006 \\
5902 \\
492 \\
216\end{array}$ & $\begin{array}{c}21603 \\
853 \\
59 \\
18\end{array}$ & $\begin{array}{c}32787 \\
435 \\
28 \\
10.46\end{array}$ & $\begin{array}{c}5.61 \cdot 10^{10} \\
1.68 \cdot 10^{5} \\
134 \\
4.8\end{array}$ & $\begin{array}{c}- \\
646 \\
80.2 \\
31.2\end{array}$ & $\begin{array}{c}- \\
121 \\
5.6 \\
2.1\end{array}$ \\
\hline
\end{tabular}




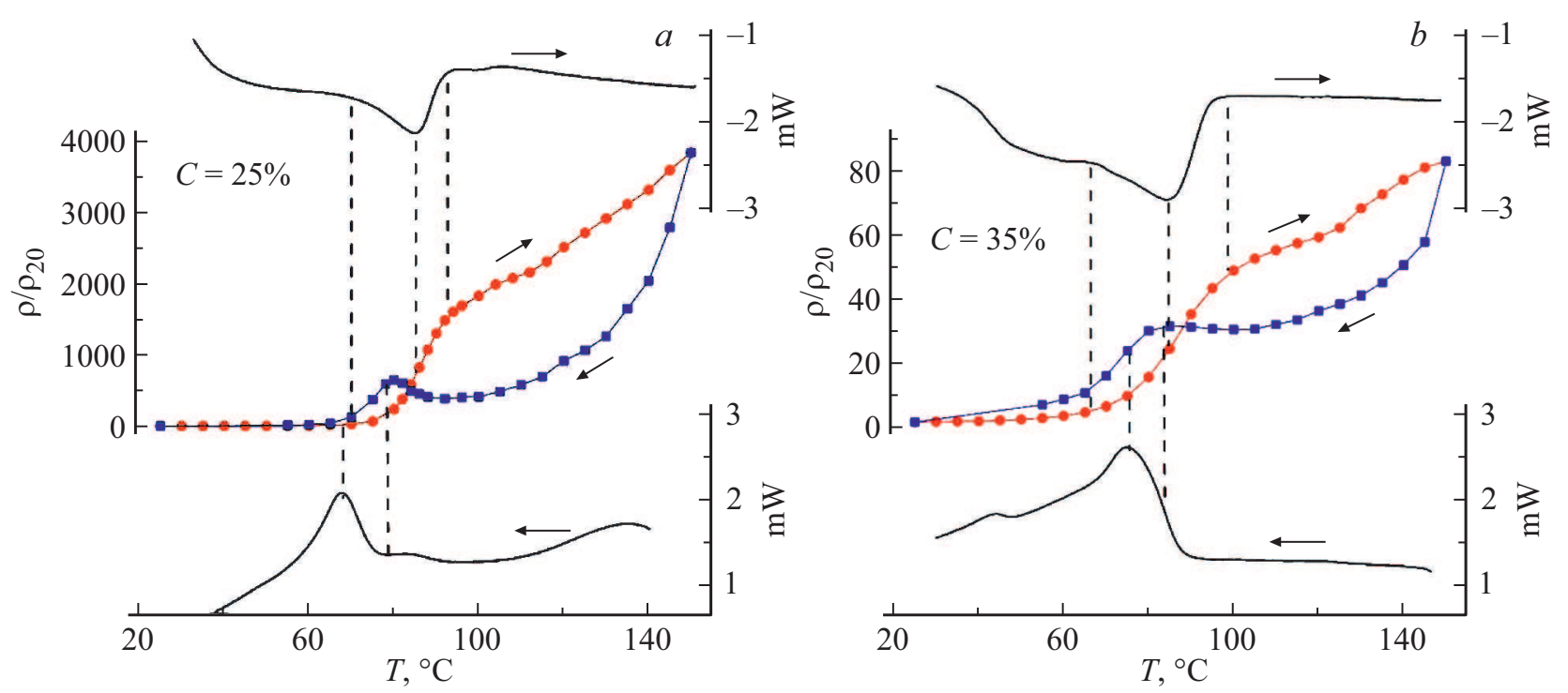

Рис. 3. Прямые и обратные температурные зависимости удельного сопротивления $\rho(T) / \rho_{20}$ композита, насыщенного пероксидом, с различным содержанием ТУ. Сверху и снизу приведены соответствующие кривые ДСК.

в 1.5 раза превышает значение ПТКС. Для образцов с бо́льшим содержанием, наоборот, ОТКС меньше (примерно в 2 раза), чем ПТКС. Кроме того, для образца с $C=15 \%$ зависимость $\rho(T)$ носит более резкий характер. Ширина пика примерно в 2 раза меньше, чем для других образцов.

Необходимо также отметить, что отличие зависимости $\rho(T)$ для образца с $C=15 \%$ от аналогичных зависимостей для образцов с бо́льшим содержанием ТУ коррелирует с величиной изменения $\rho_{20}$, происходящего в результате насыщения пероксидом (рис. 1). При такой концентрации ТУ происходит наибольшее изменение $\rho_{20}$.

Насыщение образцов пероксидом и происходящая сшивка макромолекул полимерной матрицы приводят, как отмечено выше, к существенному, особенно в области перколяции, возрастанию $\rho_{20}$ (см. таблицу) и трансформации температурной зависимости $\rho(T)$. Резкое увеличение удельного сопротивления для образца с $C=15 \%$ не позволило с достаточной точностью произвести регистрацию температурной зависимости $\rho(T)$. Для образцов с $C=25$ и $35 \%$ температурные зависимости $\rho(T) / \rho_{20}$ представлены на рис. $3, a, b$. С увеличением $C$ с 25 до $35 \%$ происходит уменьшение более чем на порядок как значения $\rho(T) / \rho_{20}$, соответствующего локальному максимуму, так и ТКС, который на обратной зависимости $\rho(T)$, а также на прямой зависимости во втором и последующих циклах нагревания дважды изменяет знак. Что касается корреляции зависимостей $\rho(T) / \rho_{20}$ с кривыми ДСК, то для сшитых композитов точка плавления полимерной кристаллической фазы также соответствует участку наиболее быстрого возрастания $\rho(T)$. Окончание процесса плавления проявляется в возникновении излома на зависимости $\rho(T) / \rho_{20}$.
Таким образом, на основе результатов, полученных в настоящей работе, можно сделать следующие выводы.

1. Установлено, что в области порога перколяции в зависимости от доминирования того или иного механизма проводимости температурная зависимость удельного объемного сопротивления полимерного композита на основе матрицы из этиленвинилацетата существенным образом трансформируется. В случае прыжкового механизма проводимости и механизма, обусловленного туннелированием, определяющее влияние на величину изменения $\rho$ оказывают термостимулированные процессы, происходящие при температурах, предшествующих точке плавления полимерной кристаллической фазы. На омический механизм проводимости наиболее существенное влияние оказывают процессы, происходящие при температуре, соответствующей окончанию плавления этой фазы.

2. С возрастанием содержания ТУ происходит уменьшение на несколько порядков не только удельного объемного сопротивления $\rho_{20}$, но и максимальной величины $\rho(T)_{\max } / \rho_{20}$ на его температурной зависимости. При этом положение максимума $\rho(T)_{\max }$ смещается в область более высоких температур.

3. Для всего исследованного диапазона концентраций ТУ наблюдается температурный гистерезис $\rho(T) / \rho_{20}$, особенно ярко проявляющийся в образцах, не насыщенных пероксидом. Это обусловлено различием в характере процессов разрушения и формирования мостиков проводимости при плавлении и кристаллизации полимерной кристаллической фазы композита.

\section{Конфликт интересов}

Авторы заявляют, что у них нет конфликта интересов. 


\section{Список литературы}

[1] Э.Р. Блайт, Д. Блур, Электрические свойства полимеров (Физматлит, М., 2008).

[2] P.J. Mather, K.M. Thomas, J. Mater. Sci., 32 (2), 401 (1997). DOI: $10.1023 / \mathrm{A}: 1018557501174$

[3] J. Aneli, G. Zaikov, O. Mukbaniani, Chem. Chem. Technol., 5 (1), 75 (2011). DOI: $10.23939 /$ chcht05.01.075

[4] M. Rahaman, T.K. Chaki, D. Khastgir, J. Mater. Sci., 48 (21), 7466 (2013). DOI: 10.1007/s10853-013-7561-9

[5] В.А. Марков, Л.Б. Кандырин, А.В. Марков, Вестн. МИТХТ, 8 (6), 103 (2013). https://elibrary.ru/download/ elibrary_21178990_95492532.pdf

[6] А.C. Степашкина, Е.С. Цобкалло, О.А. Москалюк, А.Н. Алешин, Письма в ЖТФ, 41 (2), 7 (2015). http://journals.ioffe.ru/articles/41432

[7] Т.А. Борукаев, Д.С. Гаев, Прикладная физика, № 5, 76 (2017). http://applphys.orion-ir.ru/appl-17/17-5/PF-17-5-76.pdf

[8] Б.И. Заднепровский, И.Ю. Клюев, В.Е. Турков, Письма в ЖТФ, 42 (16), 87 (2016). https://journals.ioffe.ru/articles/viewPDF/43587

[9] А.М. Зюзин, А.А. Карпеев, Н.В. Янцен, Письма в ЖТФ, 46 (12), 3 (2020). DOI: 10.21883/PJTF.2020.12.49517.18283

[10] А.М. Зюзин, А.А. Карпеев, Н.В. Янцен, Письма в ЖТФ, 46 (24), 27 (2020). DOI: 10.21883/PJTF.2020.24.50424.18486

[11] Г.С. Бочаров, А.В. Елецкий, А.А. Книжник, ЖТФ, 86 (10), 64 (2016). https://journals.ioffe.ru/articles/viewPDF/43673

[12] А.В. Елецкий, УФН, 180 (9), 897 (2010).

DOI: $10.3367 /$ UFNr.0180.201009a.0897 